\title{
The Influence of Inflammation on Fibrinogen Turnover and Redistribution of the Hemostatic Balance to a Prothrombotic State in High On-Treatment Platelet Reactivity-Dual Poor Responder (HTPR-DPR) Patients
}

\author{
Grzegorz Biolik (D, ${ }^{1}$ Dariusz Gajniak, ${ }^{2}$ Maciej Kubicz, ${ }^{1}$ Damian Ziaja, ${ }^{3}$ Krzysztof Ziaja, \\ and Waclaw Kuczmik ${ }^{1}$ \\ ${ }^{1}$ Department of General, Vascular Surgery, Angiology and Phlebology Faculty of Katowice Medical University of Silesia, Faculty of \\ Medicine in Katowice, Medical University of Silesia, Poniatowskiego Str 15, 40-055 Katowice, Poland \\ ${ }^{2}$ Department of Anaesthesiology and Intensive Care, Upper-Silesian Medical Centre of the Silesian Medical University, Ziołowa 45, \\ 40-635 Katowice, Poland \\ ${ }^{3}$ Physiotherapy Unit, Department of Physiotherapy, Faculty of Health Sciences, Medical University of Silesia, Poniatowskiego Str 15, \\ 40-055 Katowice, Poland
}

Correspondence should be addressed to Grzegorz Biolik; grzegorz.biolik@onet.pl

Received 18 January 2019; Revised 11 April 2019; Accepted 22 May 2019; Published 17 July 2019

Academic Editor: Jürgen Bernhagen

Copyright ( 2019 Grzegorz Biolik et al. This is an open access article distributed under the Creative Commons Attribution License, which permits unrestricted use, distribution, and reproduction in any medium, provided the original work is properly cited.

Knowledge about the influence of inflammation on platelet function and relocation of hemostatic balance to hypercoagulable state is still unclear. We compared two groups of patients who suffer from acute vs. chronic inflammatory process and additionally present high on-treatment platelet reactivity-dual platelet resistance. We did not found any differences in platelet aggregation between both investigated groups, but patients who suffer from chronic inflammation presented stronger relocation of the hemostatic balance to the hypercoagulability. A high concentration of prothrombin fragment F1+2 together with higher activity of von Willebrand factor in critical limb ischemia shows more exaggerated fibrinogen turnover although the blood concentration of this factor was in normal range. We concluded that high on-treatment platelet reactivity-dual platelet resistance and intensified inflammation are linked with elevated platelet and fibrinogen turnover to counteract proper hemostatic balance in favor of a prothrombotic state.

\section{Introduction}

Platelets play a key role in the pathophysiology of coronary, cerebral, and peripheral artery diseases, and platelets are especially a key in arterial thrombosis [1-9]. The significance and impact of acute and chronic inflammatory processes on platelet function, clot formation, and atherogenesis are still unclear; however, these processes seem to play a pivotal role in the reallocation of hemostatic balance to a hypercoagulable state $[1,10-15]$. Knowledge about the influence of inflammation on platelet function, not only is regarded to thrombus formation, may result in the development of more clinically effective treatment strategies and a better understanding of HTPR-DPR.

\section{Aim}

The aim of our study was to show the influence of weak vs. strong inflammatory reactions on the movement of hemostatic balance towards a hypercoagulable state due to increased fibrinogen turnover in patients who have normal concentrations of this clotting factor in their blood. The changes in hemostatic balance were assessed in two groups 
of patients: an AMI group (acute myocardial infarction) and a CLI group (critical limb ischemia).

\section{Material and Methods}

This study was performed on two groups of patients who suffered from HTPR-DPR: 23 CLI patients who qualified for tight amputation due to advanced necrotic changes (Rutherford class 6). There were also 26 AMI patients who qualified for the study; the AMI patients were included 3-5 days after percutaneous coronary intervention (PCI), drug-eluting stent (DES) implantation to the coronary arteries, and additionally suffered from low ejection fraction (EF) $<45 \%$.

Common inclusion criteria were as follows: all investigated patients received dual antiplatelet therapy (DAPT), $75 \mathrm{mg}$ of clopidogrel and $75 \mathrm{mg}$ of aspirin daily. Contrary to the CLI group, all AMI patients received a loading dose of clopidogrel $(600 \mathrm{mg})$ and aspirin $(300 \mathrm{mg}$ ) just before the endovascular procedure on the day of admission to the hospital. All patients suffered from HTPR-DPR. HTPR-DPR was defined as the area under the curve (AUC) from Multiplate ${ }^{\circledast}$ impedance aggregometry: HTPR-DPR was defined as AUC > 436 for the ADP test and $>300$ AUC for the ASPI test. All patients presented with a normal blood fibrinogen concentration (e.g., 1.8-3.5 g/L) and elevated blood concentration of C-reactive protein (e.g., $>5 \mathrm{mg} / \mathrm{L}$ ). The detailed characteristics of both investigated groups are presented in Table 1.

The exclusion criteria were as follows: diabetes, arrhythmia, chronic kidney diseases (CKD) in stage $3 \mathrm{~B}$ or higher, or receiving additional oral anticoagulation.

All of the study participants provided written consent to take part in the study after reading the study protocol.

The study was conducted after obtaining permission from the Local Bioethical Commission within a broader research project concerning platelet hyperreactivity in patients with critical limb ischemia.

3.1. Blood Sampling. Venous blood was collected into citrate vacutainer tubes $\left(3.2 \%\right.$ sodium citrate) for ROTEM ${ }^{\circledast}$ analysis and into hirudin vacutainer tubes $(15.4 \mu \mathrm{g} / \mathrm{mL}$, final concentration of hirudin) for Multiplate investigations. Obtained samples were evaluated within $15 \mathrm{~min}$, and the reagents for both methods were used following the manufacturer's recommendations.

3.2. Thromboelastometry. Rotational thromboelastometry was performed with a ROTEM ${ }^{\circledast}$ Delta (TEM International, Munich, Germany). Two tests were performed, EXTEM and FIBTEM, according to the standard protocols supplied by the manufacturer. The following parameters were analyzed: clotting time (CT), clot formation time (CFT), amplitude after $10 \mathrm{~min}$ of measurement (A10), amplitude after 20 min of measurement (A20), and maximum clot firmness (MCF) for EXTEM and A10, A20 and MCF for FIBTEM. Calibration of the device was performed by representatives of the manufacturers. Quality control was performed every day before measurements. The "hypercoagulable profile" was recognized when the value of MCF was above the upper limit of the norm for MCF (e.g., supranormal value of $\mathrm{MCF}>70 \mathrm{~mm}$ for EXTEM or $>25 \mathrm{~mm}$ for FIBTEM using definitions described by Görlinger et al.) [10].

3.3. Aggregometry. Impedance aggregometry measurements were performed on a Multiplate function analyzer (Dynabate Information System, Munich, Germany; with software version V2.03.11) using the standard reagents and protocols recommended by the manufacturer for the four tests: ADP, ASPI, COL, and TRAP. Aggregation was measured as the area under the curve $\left(\mathrm{AUC} / \mathrm{mm}^{2}\right)$. As mentioned previously, HTPR-DPR was diagnosed when the AUC was $>436$ for the ADP test and $>300$ for the ASPI test. Similar to thromboelastometry, the calibration was performed by representatives of the manufacturer, and quality control was performed every day before measurement.

3.4. Statistical Analysis. All data were presented as the mean \pm standard deviation for normally distributed variables and as medians and percentages for nonnormally distributed variables. For further comparisons between both groups, the following tests were used: Wilcoxon, Mann-Whitney $U$, and other nonparametric alternatives for the analysis of variance, and Kruskal-Wallis. Statistica 9 software (StatSoft Inc., Tulsa, USA) was used for the statistical data analysis.

\section{Results}

4.1. Aggregometry. In terms of blood platelet aggregation, the ADP, ASPI, COL, and TRAP tests did not reveal any statistically significant differences between the investigated groups. The results are presented in Table 2.

4.2. Thromboelastometry. EXTEM test analysis showed that all patients in the CLI group presented "supranormal" values on the MCF test (hypercoagulability), while the AMI group results were between "normal" and "supranormal" for the same test. On the other hand, FIBTEM test analysis showed unequivocally "supranormal" values on the MCF test (hypercoagulability) in the CLI group and "normal" (9-25 mm) values in the AMI group. The results are presented in Table 3.

4.3. Laboratory Tests. The fibrinogen concentration was within normal values in both groups, and there was no statistically significant difference between groups.

There was no statistically significant difference in mean platelet volume (MPV) between both groups. Interestingly, the mean value of MPV was above $9 \mathrm{fL}$ in both groups. This finding may be associated with an increased fraction of immature platelets.

In terms of inflammatory process assessment, the values of hs-CRP were significantly higher in the CLI group than in the AMI group.

The von Willebrand factor (vWF) activity levels were significantly higher in the CLI group, but there was no difference in vWF antigen concentration between the groups. The results demonstrated not only a higher intensity of inflammatory processes in patients qualified for amputation but also a shift in hemostatic balance towards hypercoagulable state. 
TABLE 1: Characteristics of the study group.

\begin{tabular}{|c|c|c|c|}
\hline & CLI & AMI & $P$ value \\
\hline Age (yrs) & $66 \pm 4.2$ & $63 \pm 7.6$ & NS \\
\hline Male sex, $n(\%)$ & $21(91.3)$ & $19(88.4)$ & NS \\
\hline BMI $\left(\mathrm{kg} / \mathrm{m}^{2}\right)$ & $21.1 \pm 1.9$ & $22.3 \pm 1.1$ & NS \\
\hline INR $(r . v .0 .8-1.2)$ & $1.0 \pm 0.05$ & $0.9 \pm 0.07$ & NS \\
\hline Index APTT (r.v. 0.84-1.16) & $0.93 \pm 0.1$ & $0.98 \pm 0.7$ & NS \\
\hline Fibrinogen (g/L) (r.v. 1.5-4.5) & $3.0 \pm 0.5$ & $2.8 \pm 0.5$ & NS \\
\hline Platelets $\left(\times 10^{9} / \mathrm{L}\right)($ r.v. $150-450)$ & $283.2 \pm 91.3$ & $219.8 \pm 44.1$ & NS \\
\hline Platelet distribution width (\%) (r.v. 8.0-18.0) & $13.6 \pm 3.2$ & $17.2 \pm 2.1$ & NS \\
\hline Mean platelet volume (fL) (r.v. 8.0-12.0) & $9.3 \pm 1.6$ & $9.3 \pm 0.7$ & NS \\
\hline White blood cells $\left(\times 10^{9} / \mathrm{L}\right)($ r.v. $4.5-10.0)$ & $10.2 \pm 3.0$ & $9.4 \pm 1.9$ & NS \\
\hline Red blood cells $\left(\times 10^{12} / \mathrm{L}\right)($ r.v. 4.5-5.5) & $4.4 \pm 0.5$ & $4.6 \pm 0.2$ & NS \\
\hline Hemoglobin (g/dL) (r.v. 13.0-18.0) & $14.37 \pm 1.4$ & $14.0 \pm 1.8$ & NS \\
\hline Hematocrit (\%) (r.v. 40-54) & $42.6 \pm 4.9$ & $41.3 \pm 5.4$ & NS \\
\hline hs-CRP (mg/L) (r.v. <5.0) & $60.8 \pm 12.9$ & $6.4 \pm 3.1$ & $<0.006$ \\
\hline Thrombomodulin $(\mu \mathrm{g} / \mathrm{L})($ r.v. 1.8-4.4) & $2.36 \pm 0.74$ & $2.63 \pm 0.78$ & NS \\
\hline von Willebrand antigen $(\mathrm{U} / \mathrm{mL})($ r.v. $0.51-7.71)$ & $5.02 \pm 1.35$ & $4.41 \pm 1.15$ & NS \\
\hline von Willebrand activity (\%) (r.v. 55-140) & $65.6 \pm 16.4$ & $36.7 \pm 11.1$ & $<0.01$ \\
\hline Prothrombin fragment $\mathrm{F} 1+2(\mathrm{nmol} / \mathrm{L})($ r.v. $0.2-2.78)$ & $4.02 \pm 2.2$ & $2.28 \pm 1.7$ & $<0.01$ \\
\hline Tissue factor $(\mu \mathrm{g} / \mathrm{L})(r . v .28-255)$ & $123.1 \pm 26.0$ & $107.8 \pm 31.4$ & NS \\
\hline
\end{tabular}

Abbreviations: CLI: critical limb ischemia; AMI: acute myocardial infarction; BMI: body mass index; hs-CRP: high-sensitivity C-reactive protein.

TABLE 2: Results of aggregometric findings.

\begin{tabular}{lccc}
\hline MEA (AUC) & & & \\
\hline ADP $\left(\mathrm{mm}^{2}\right)($ r.v. 534-1220) & $866.8 \pm 113.8$ & $769.8 \pm 138.5$ & NS \\
ASPI $\left(\mathrm{mm}^{2}\right)($ r.v. $745-1361)$ & $485.3 \pm 167.1$ & $412.6 \pm 98.7$ & NS \\
COL $\left(\mathrm{mm}^{2}\right)$ (r.v. 459-1166) & $722.7 \pm 196.2$ & $625.8 \pm 151.8$ & NS \\
TRAP $\left(\mathrm{mm}^{2}\right)$ (r.v. 941-1563) & $1494.9 \pm 226.1$ & $1364.9 \pm 440.0$ & NS
\end{tabular}

Abbreviations: ADP/ASPI/COL or TRAP: standard test; AUC: area under the curve $\left(\mathrm{mm}^{2}\right)$; r.v.: referential value.

There was also a statistically significant difference in the concentration of prothrombin fragment $1+2(\mathrm{~F} 1+2)$ between groups, with higher values in the CLI population. Importantly, the mean concentration was above the upper limit of the normal range in both groups. This observation suggests that the process of increased fibrinogen turnover is present in both groups but is more exaggerated in the CLI group.

\section{Discussion}

Clinically, elevated hs-CRP levels and HTPR have been characterized as important risk factors for adverse ischemic cardiovascular events, although the data are still controversial [1,11-20]. In many papers, both are presented as independent risk factors for myocardial infarction (MI), periprocedural myocardial infarction (PMI), or stent thrombosis. C-reactive protein (CRP) plays an important role in the processes
TABLE 3: Results of thromboelastometric findings.

\begin{tabular}{lccc}
\hline EXTEM & CLI & AMI & P value \\
\hline CT (s) (r.v. 38-79) & $52.5 \pm 8.0$ & $50.6 \pm 5.4$ & NS \\
CFT (s) (r.v. 34-159) & $50.3 \pm 17.4$ & $71.4 \pm 15.5$ & $<0.04$ \\
A10 (mm) (r.v. 43-65) & $70.0 \pm 7.7$ & $63.0 \pm 4.4$ & $<0.01$ \\
A20 (mm) (r.v. 50-71) & $73.5 \pm 6.5$ & $68.2 \pm 3.8$ & $<0.02$ \\
MCF (mm) (r.v. 50-72) & $73.9 \pm 6.3$ & $69.0 \pm 3.5$ & $<0.03$ \\
INTEM & & & \\
CT (s) (r.v. 100-240) & $184 \pm 7.3$ & $247.5 \pm 11.2$ & NS \\
CFT (s) (r.v. 30-110) & $54.5 \pm 7.75$ & $79 \pm 10.9$ & NS \\
A10 (mm) (r.v. 44-66) & $62 \pm 9.6$ & $60.5 \pm 9.35$ & NS \\
A20 (mm) (r.v. 50-71) & $67 \pm 9.93$ & $66 \pm 9.15$ & NS \\
MCF (mm) (r.v. 50-72) & $67 \pm 9.81$ & $66.5 \pm 9.25$ & NS \\
FIBTEM & & & \\
A10 (mm) (r.v. 7-23) & $32.1 \pm 13.6$ & $20.5 \pm 5.7$ & $<0.01$ \\
A20 (mm) (r.v. 8-24) & $33.3 \pm 14.0$ & $21.7 \pm 5.9$ & $<0.01$ \\
MCF (mm) (r.v. 9-25) & $33.6 \pm 14.1$ & $21.9 \pm 6.1$ & $<0.02$ \\
\hline
\end{tabular}

Abbreviations: CT: clotting time; CFT: clot formation time; A10: amplitude after 10 min of measurement; A20: amplitude after 20 min of measurement; MCF: maximum clot firmness; r.v.: referential value of CT, CFT, A10, A20, and MCF for specific test. EXTEM, INTEM, and FIBTEM are standard tests. 
of thrombogenesis and thromboembolism [1, 21-25]. Together with other proinflammatory cytokines, it plays an important role in the production of clotting factors that contribute to an enhanced prothrombotic state [4, 25-27]. These disturbances in the hemostatic system are mainly mediated by the increased production of fibrinogen and von Willebrand factor as well as platelet activation; in cases of intensified inflammation, there is observed increased turnover fibrinogen, von Willebrand factor, and platelets $[15,26,28-31]$. Therefore, the blood concentration of some of these factors may be in a normal range and falsely suggest a normocoagulable state.

Routine laboratory assays for prothrombin time and activated partial thromboplastin time are unable to detect a hypercoagulable state because they do not entirely reflect overall hemostatic balance $[32,33]$.

Two methods, rotational thromboelastometry ROTEM ${ }^{\circledR}$ and Multiplate ${ }^{\circledast}$ aggregometry, are useful for recognizing a hypercoagulable state related to participation of platelets, fibrinogen, and factor XIII [17, 31-34].

ROTEM $^{\circledast}$ provides further information about thrombus generation and total clot strength that closely correlates with plasma thrombogram assays, the gold standard test for thrombin generation. In this method, fibrin-based clot strength is dependent mainly on fibrinogen and factor XIII concentrations, while the platelet component of clot strength is defined as the difference in shear modulus measured with and without platelet inhibition $\left(\mathrm{MCE}_{\text {platelet }}=\mathrm{MCE}_{\mathrm{EXTEM}}-\mathrm{MCE}_{\mathrm{FIBTEM}}\right)$ $[17,29,31-36]$. This suggests that platelet contribution in overall clot strength in ROTEM $^{\circledast}$ is related to binding and tightening of the fibrin fibers. The main limitation of this method is the lack of permanent inhibition of platelet activity in the FIBTEM test, even in healthy subjects. This limitation was described by Michos and many other investigators [19]. The last observations show that, in HTPR patients, the platelet aggregation ability is many times stronger, and aggregation is still observed (as the residual) if cytochalasin D and IIb/IIIa inhibitors are used [31-35, 37-40].

Analysis of the ROTEM ${ }^{\circledast}$ amplitude (A) and maximum clot firmness (MCF) values for the EXTEM and FIBTEM tests carried out by Görlinger et al. provided the scientific basis for the division of the treated patients into three groups, subnormal, normal, and supranormal, according to the reference ranges for these tests [17].

The ROTEM ${ }^{\circledast}$ supranormal values for amplitude (A) and maximum clot firmness (MCF) suggest a hypercoagulable state but do not offer simple reason for this state [17].

We analyzed two groups of patients with HTPR-DPR. There were no statistically significant differences in the intensification of HTPR-DPR (platelet aggregation), PLT count, fibrinogen concentration or, most importantly, tissue factor, and thrombomodulin concentrations. In both investigated groups, we observed intensified von Willebrand factor activity and an increased prothrombin factor F1+2 concentration that was more intensified in the CLI group. Because there is a strong and linear correlation between the concentration of this protein $(\mathrm{F} 1+2)$ and the intensification of fibrinogen degradation, it seems that the differences observed in EXTEM and FIBTEM were not related to platelets but were related to the other clotting factors, mainly to fibrinogen degradation and turnover.

It seems that the ROTEM ${ }^{\circledast}$ may be a promising method for recognizing high risk patients who suffer from HTPRDPR because comparison of HTPR-DPR, factor F1+2 concentration, and the results of EXTEM/FIBTEM could be helpful for proper recognition of the inflammatory impact on hemostatic balance and for estimation of the real risk of thrombosis. It may be helpful for DAPT modification (such as for a drug's dosage) with or without additional anticoagulation to achieve tailored (personalized) therapy without increasing the risk of bleeding. However, as was shown by P. Gurbel and his team, there are not any methods that can simultaneously measure and analyze the relationships between inflammation (demonstrated by different elevated markers), platelet reactivity, and hypercoagulability $[1,10,17]$. Therefore, further research for strategies specifically targeting high-risk patients seems to be necessary and would be useful for personalized therapeutic management.

\section{Conclusion}

HTPR-DPR and intensified inflammation are linked with elevated platelet and fibrinogen turnover to counteract proper hemostatic balance in favor of a prothrombotic state.

\section{Study Limitations}

This study was a pilot investigation. The relatively small number of investigated patients in both groups was the reason for a very restrictive inclusion and exclusion criteria; notably, we had to eliminate cardiac patients who suffered from acute bacterial or viral infections.

In the paper, we did not analyze the D-dimer concentration between the two groups. The D-dimer concentration was very high in the CLI group due to thrombosis in ischemic/necrotic limbs; therefore, the groups were not comparable.

\section{Data Availability}

The database and the results are available for reviewers.

\section{Conflicts of Interest}

The authors have no conflicts of interest to disclose.

\section{References}

[1] J. S. Woo, W. Kim, H. H. Jang, J. B. Kim, W. S. Kim, and K. S. Kim, "Effect of platelet reactivity, endothelial function, and inflammatory status on outcomes in patients with stable angina pectoris on clopidogrel therapy," The American Journal of Cardiology, vol. 113, no. 5, pp. 786-792, 2014.

[2] W. Ye, C. W. Liu, J. B. Ricco, K. Mani, R. Zeng, and J. Jiang, "Early and late outcomes of percutaneous treatment of TransAtlantic Inter-Society Consensus class C and D aorto-iliac lesions," Journal of Vascular Surgery, vol. 53, no. 6, pp. 17281737, 2011.

[3] A. W. Bradbury, D. J. Adam, J. Bell et al., "Bypass versus Angioplasty in Severe Ischaemia of the Leg (BASIL) trial: 
analysis of amputation free and overall survival by treatment received," Journal of Vascular Surgery, vol. 51, no. 5, pp. 18S-31S, 2010.

[4] F. Saia, M. Marino, G. Campo et al., "Incidence and outcome of high on-treatment platelet reactivity in patients with nonST elevation acute coronary syndromes undergoing percutaneous coronary intervention (from the VIP [VerifyNow and Inhibition of Platelet Reactivity] study)," American Journal of Cardiology, vol. 112, no. 6, pp. 792-798, 2013.

[5] A. Farber, K. Rosenfield, and M. Menard, "The BEST-CLI trial: a multidisciplinary effort to assess which therapy is best for patients with critical limb ischemia," Techniques in Vascular and Interventional Radiology, vol. 17, no. 3, pp. 221-224, 2014.

[6] T. Cuisset, C. Frere, J. Quilici et al., "High post-treatment platelet reactivity identified low-responders to dual antiplatelet therapy at increased risk of recurrent cardiovascular events after stenting for acute coronary syndrome," Journal of Thrombosis and Haemostasis, vol. 4, no. 3, pp. 542-549, 2006.

[7] J. L. Mills Sr, M. S. Conte, D. G. Armstrong et al., “The Society for Vascular Surgery lower extremity threatened limb classification system: risk stratification based on wound, ischemia, and foot infection (WIfI)," Journal of Vascular Surgery, vol. 59, no. 1, pp. 220-234.e2, 2014.

[8] M. Jakl, R. Sevcik, I. Fatorova, J. M. Horacek, and R. Pudil, "High on-treatment platelet reactivity: risk factors and 5-year outcomes in patients with acute myocardial infarction," The Anatolian Journal of Cardiology, vol. 17, no. 2, pp. 113-118, 2017.

[9] P. A. Gurbel, K. P. Bliden, K. Guyer et al., "Platelet reactivity in patients and recurrent events post-stenting: results of the PREPARE POST-STENTING study," Journal of the American College of Cardiology, vol. 46, no. 10, pp. 1820-1826, 2005.

[10] D. J. Angiolillo, E. Bernardo, M. Sabaté et al., "Impact of Platelet Reactivity on Cardiovascular Outcomes in Patients With Type 2 Diabetes Mellitus and Coronary Artery Disease," Journal of the American College of Cardiology, vol. 50, no. 16, pp. 1541-1547, 2007.

[11] M. Samoš, R. Šimonová, F. Kovář et al., "Clopidogrel resistance in diabetic patient with acute myocardial infarction due to stent thrombosis," American Journal of Emergency Medicine, vol. 32, no. 5, pp. 461-465, 2014.

[12] G. Campo, G. Parrinello, P. Ferraresi et al., "Prospective Evaluation of On-Clopidogrel Platelet Reactivity Over Time in Patients Treated With Percutaneous Coronary Intervention," Journal of the American College of Cardiology, vol. 57, no. 25, pp. 2474-2483, 2011.

[13] O. Muller, M. Hamilos, J. Bartunek et al., "Relation of endothelial function to residual platelet reactivity after clopidogrel in patients with stable angina pectoris undergoing percutaneous coronary intervention," American Journal of Cardiology, vol. 105, no. 3, pp. 333-338, 2010.

[14] M. Chatterjee and T. Geisler, "Inflammatory Contribution of Platelets Revisited: New Players in the Arena of Inflammation," Seminars in Thrombosis and Hemostasis, vol. 42, no. 03, pp. 205-214, 2016.

[15] L. Perl, H. Lerman-Shivek, E. Rechavia et al., "Response to prasugrel and levels of circulating reticulated platelets in patients with ST-segment elevation myocardial infarction," Journal of the American College of Cardiology, vol. 63, no. 6, pp. 513$517,2014$.

[16] C. C. F. M. J. Baaten, L. F. Veenstra, R. Wetzels et al., "Gradual increase in thrombogenicity of juvenile platelets formed upon offset of prasugrel medication," Haematologica, vol. 100, no. 9, pp. 1131-1138, 2015.

[17] K. Görlinger, D. Dirkmann, C. Solomon, and A. A. Hanke, "Fast interpretation of thromboelastometry in non-cardiac surgery: reliability in patients with hypo-, normo-, and hypercoagulability," British Journal of Anaesthesia, vol. 110, no. 2, pp. 222-230, 2013.

[18] T. H. Wang, D. L. Bhatt, and E. J. Topol, “Aspirin and clopidogrel resistance: an emerging clinical entity," European Heart Journal, vol. 27, no. 6, pp. 647-654, 2006.

[19] E. D. Michos, R. Ardehali, R. S. Blumenthal, R. A. Lange, and H. Ardehali, "Aspirin and clopidogrel resistance," Mayo Clinic Proceedings, vol. 81, no. 4, pp. 518-526, 2006.

[20] E. Jover, J. M. Rodríguez, A. Bernal et al., "High on-treatment platelet reactivity in patients with ischemic cerebrovascular disease: assessment of prevalence and stability over time using four platelet function tests," Blood Coagulation \& Fibrinolysis, vol. 25, no. 6, pp. 604-611, 2014.

[21] T. Hoefer, P. C. Armstrong, M. Finsterbusch, M. V. Chan, N. S. Kirkby, and T. D. Warner, "Drug-free platelets can act as seeds for aggregate formation during antiplatelet therapy," Arteriosclerosis, Thrombosis, and Vascular Biology, vol. 35, no. 10, pp. 2122-2133, 2015.

[22] W. Otter, M. Winter, W. Doering, E. Standl, and O. Schnell, "C-reactive protein in diabetic and nondiabetic patients with acute myocardial infarction," Diabetes Care, vol. 30, no. 12, pp. 3080-3082, 2007.

[23] R. Marcucci, A. Gori, R. Paniccia et al., "High on-treatment platelet reactivity by more than one agonist predicts 12 month follow-up cardiovascular death and non-fatal myocardial infarction in acute coronary syndrome patients receiving coronary stenting," Thrombosis and Haemostasis, vol. 104, no. 08, pp. 279-286, 2010.

[24] G. G. L. Biondi-Zoccai, A. Abbate, G. Liuzzo, and L. M. Biasucci, "Atherothrombosis, inflammation, and diabetes," Journal of the American College of Cardiology, vol. 41, no. 7, pp. 1071-1077, 2003.

[25] M. K. Freynhofer, V. Bruno, J. Wojta, and K. Huber, "The Role of Platelets in Athero-Thrombotic Events," Current Pharmaceutical Design, vol. 18, no. 33, pp. 5197-5214, 2012.

[26] P. A. Gurbel, K. P. Bliden, R. P. Kreutz, J. Dichiara, M. J. Antonino, and U. S. Tantry, "The link between heightened thrombogenicity and inflammation: Pre-procedure characterization of the patient at high risk for recurrent events after stenting," Platelets, vol. 20, no. 2, pp. 97-104, 2009.

[27] M. K. Freynhofer, S. C. Gruber, E. L. Grove, T. W. Weiss, J. Wojta, and K. Huber, "Antiplatelet drugs in patients with enhanced platelet turn-over: biomarkers versus platelet function testing," Thrombosis and Haemostasis, vol. 114, no. 3, pp. 459-468, 2015.

[28] G. Patti, F. Mangiacapra, E. Ricottini et al., "Correlation of platelet reactivity and C-reactive protein levels to occurrence of peri-procedural myocardial infarction in patients undergoing percutaneous coronary intervention (from the ARMYDACRP study)," American Journal of Cardiology, vol. 111, no. 12, pp. 1739-1744, 2013.

[29] W. Sumaya, L. Wallentin, S. K. James et al., "Fibrin clot properties independently predict adverse clinical outcome following acute coronary syndrome: a PLATO substudy," European Heart Journal, vol. 39, no. 13, pp. 1078-1085, 2018. 
[30] M. R. Thomas and G. Y. H. Lip, "Novel risk markers and risk assessments for cardiovascular disease," Circulation Research, vol. 120, no. 1, pp. 133-149, 2017.

[31] D. N. Kalkman, M. Aquino, B. E. Claessen et al., "Residual inflammatory risk and the impact on clinical outcomes in patients after percutaneous coronary interventions," European Heart Journal, vol. 39, no. 46, pp. 4101-4108, 2018.

[32] P. Taura, E. Rivas, G. Martinez-Palli et al., "Clinical markers of the hypercoagulable state by rotational thrombelastometry in obese patients submitted to bariatric surgery," Surgical Endoscopy, vol. 28, no. 2, pp. 543-551, 2014.

[33] E. Campello, L. Spiezia, E. Zabeo, S. Maggiolo, R. Vettor, and P. Simioni, "Hypercoagulability detected by whole blood thromboelastometry (ROTEM ${ }^{\circledR}$ ) and impedance aggregometry (MULTIPLATE ${ }^{\circledR}$ ) in obese patients," Thrombosis Research, vol. 135, no. 3, pp. 548-553, 2015.

[34] C. J. Schlimp, C. Solomon, M. Ranucci, G. Hochleitner, H. Redl, and H. Schöchl, "The effectiveness of different functional fibrinogen polymerization assays in eliminating platelet contribution to clot strength in thromboelastometry," Anesthesia \& Analgesia, vol. 118, no. 2, pp. 269-276, 2014.

[35] C. Solomon, M. Ranucci, G. Hochleitner, H. Schöchl, and C. J. Schlimp, "Assessing the Methodology for Calculating Platelet Contribution to Clot Strength (Platelet Component) in Thromboelastometry and Thrombelastography," Anesthesia and Analgesia, vol. 121, no. 4, pp. 868-878, 2015.

[36] J. Li, Z. Jian, M. Song et al., "Tailored antiplatelet therapy and clinical adverse outcomes," Heart, vol. 100, no. 1, pp. 41-46, 2014.

[37] C. Solomon, E. Baryshnikova, C. J. Schlimp, H. Schöchl, L. M. Asmis, and M. Ranucci, "FIBTEM PLUS provides an improved thromboelastometry test for measurement of fibrin-based clot quality in cardiac surgery patients," Anesthesia and Analgesia, vol. 117, no. 5, pp. 1054-1062, 2013.

[38] N. J. BREET, J. W. van WERKUM, H. J. BOUMAN, J. C. KELDER, J. M. ten BERG, and C. M. HACKENG, "High onaspirin platelet reactivity as measured with aggregation-based, cyclooxygenase- 1 inhibition sensitive platelet function tests is associated with the occurrence of atherothrombotic events," Journal of Thrombosis and Haemostasis, vol. 8, no. 10, pp. 2140-2148, 2010.

[39] M. Lordkipanidze, C. Pharand, E. Schampaert, J. Turgeon, D. A. Palisaitis, and J. G. Diodati, "A comparison of six major platelet function tests to determine the prevalence of aspirin resistance in patients with stable coronary artery disease," European Heart Journal, vol. 28, no. 14, pp. 1702-1708, 2007.

[40] S. G. CHU, R. C. BECKER, P. B. BERGER et al., "Mean platelet volume as a predictor of cardiovascular risk: a systematic review and meta-analysis," Thrombosis and Haemostasis, vol. 8, no. 1, pp. 148-156, 2010. 


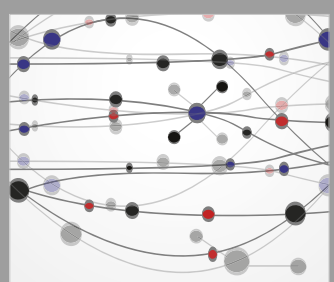

The Scientific World Journal
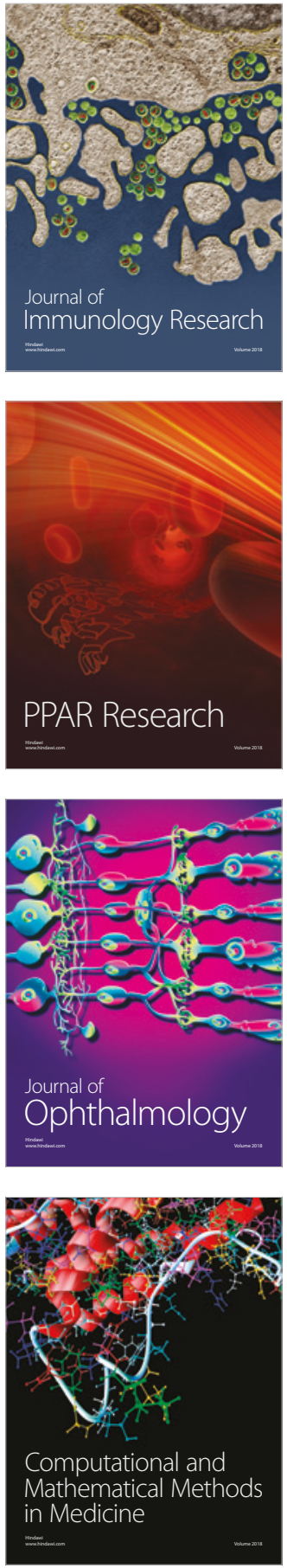

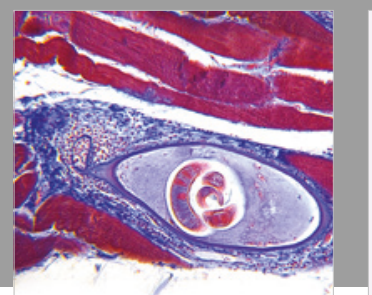

Gastroenterology Research and Practice

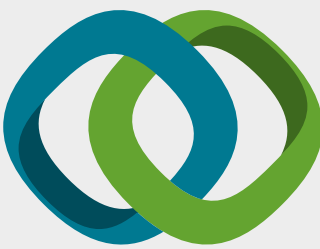

\section{Hindawi}

Submit your manuscripts at

www.hindawi.com
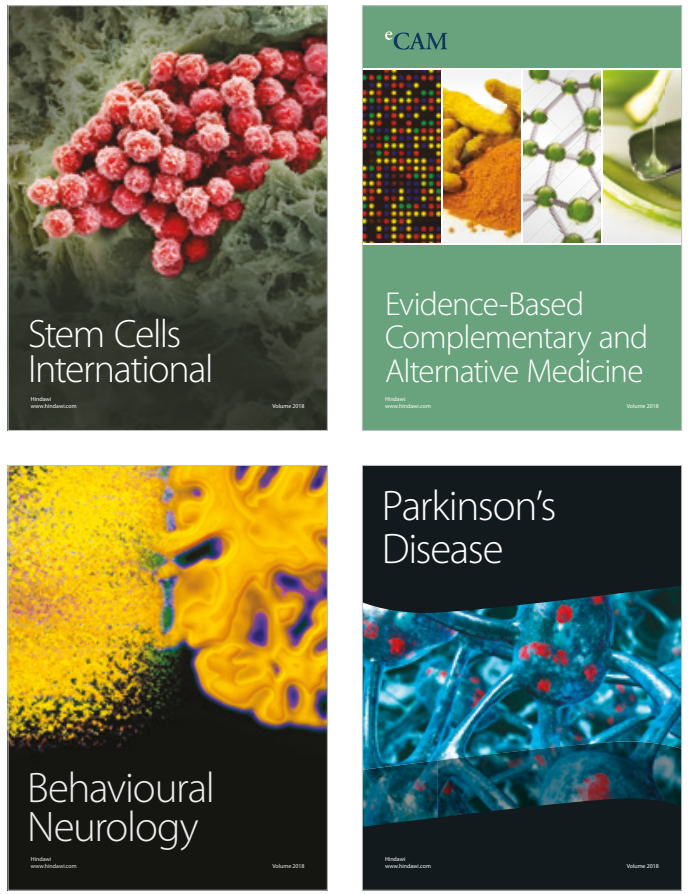

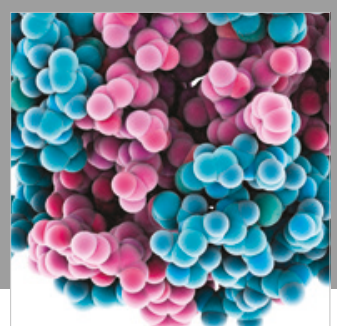

ournal of

Diabetes Research

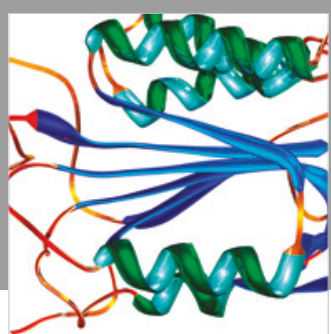

Disease Markers
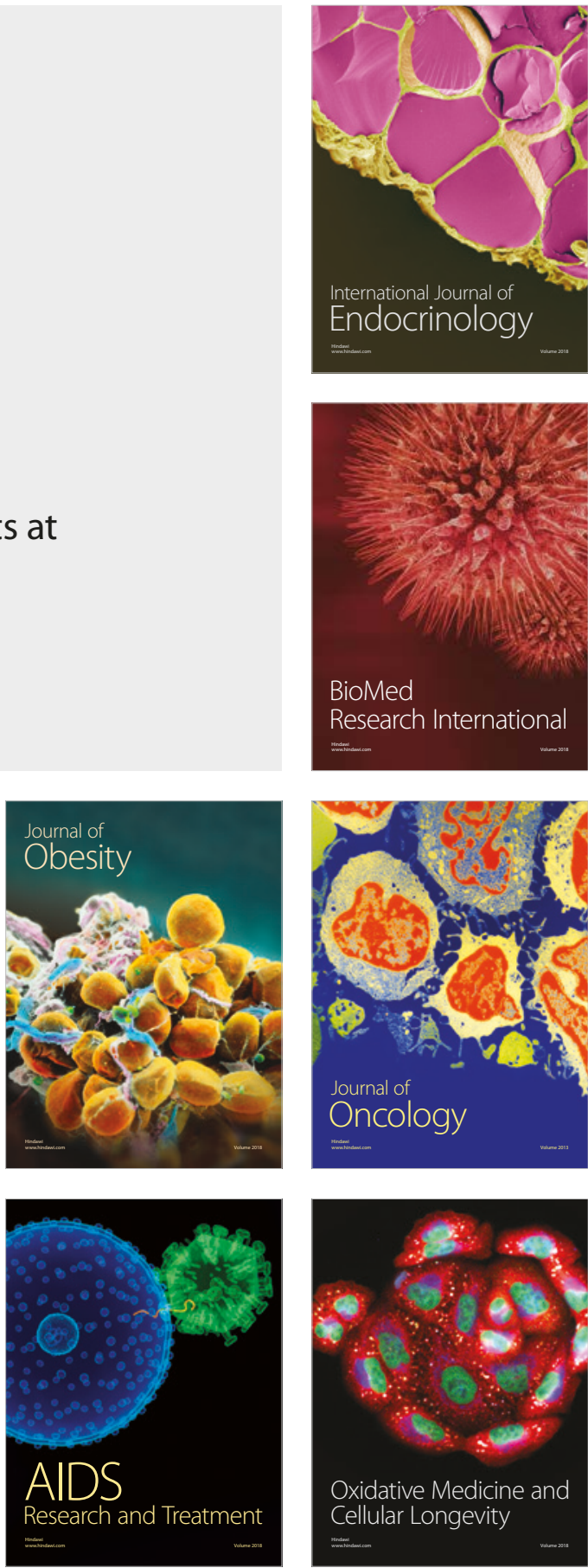